\title{
Los libros impresos para el obispado de Oviedo por Agustín de Paz (1555-1559): un ejemplo de proyecto editorial diocesano durante el Concilio de Trento
}

\author{
Benito Rial ${ }^{1}$ \\ Recibido: 28 septiembre 2017 / Aceptado: 20 de noviembre de 2017
}

Resumen: En 1547 Cristóbal de Rojas y Sandoval se hacía cargo del obispado de Oviedo, dando inicio, poco tiempo después, a una importante reforma en el obispado. En 1550 su cabildo había comenzado a trabajar en un nuevo breviario y, en 1553, se ponía en marcha un ambicioso proyecto editorial con el que reformar la diócesis. Este artículo reúne documentación del Archivo de la Catedral de Oviedo, del Archivo del Reino de Galicia y del Archivo Histórico Universitario de Santiago para narrar los detalles de la compleja y accidentada historia de este proyecto y de los trabajos realizados para él por el impresor Agustín de Paz entre 1555 y 1559. La abundante documentación que se incluye en este artículo también aporta numerosos detalles acerca del proceso de producción de estos trabajos y de las personas envueltas en él e informa de la financiación del proyecto editorial a través de la publicación de indulgencias y del mercado ilegal de éstas en un momento de convulsión religiosa.

Palabras clave: Cristóbal de Rojas; Agustín de Paz; reforma; imprenta; Oviedo; siglo XVI; Trento; breviario; Misal; Sínodo; Constituciones sinodales; Bula; Indulgencia; Libro litúrgico.

\section{[en] The books printed by Agustín de Paz for the bishopric of Oviedo (1555-1559): A case-study of a diocesan publishing project during the Council of Trent}

\begin{abstract}
In 1547, Cristóbal de Rojas and Sandoval ascended to the bishopric of Oviedo, and, shortly afterward, a major reform in the bishopric was begun. In 1550, its council had started to work on a new breviary, and, in 1553, an ambitious publishing project was put in place for reforming the diocese. This article brings together documentation kept at the Archivo de la Catedral de Oviedo, Archivo del Reino de Galicia, and Archivo Histórico Universitario de Santiago to narrate the details of the complex and uneven story of this project and the works printed by Augustin de Paz between 1555 and 1559 for it. The abundant documentation included in this article also provides many details of the production process of these works and the people involved and informs of the financing of the publishing project through the publication of indulgences and of their illegal market in a moment of religious convulsion.
\end{abstract}

Keywords: Cristóbal de Rojas; Agustín de Paz; Reform; Printing; Oviedo; Sixteenth century; Trent;

1 Universidad Complutense de Madrid. Grupo de Investigación Bibliopegia. Departamento de Bibliografía Española y Literatura Hispanoamericana. Filología IV

E-mail: brial@ucm.es 
breviary; Missal; Synod; Synodal costitutions; Bull; Indulgence; Liturgical book.

Sumario. 1. Cristóbal de Rojas y el proyecto editorial oventense. 2. Agustín de Paz en Oviedo y su accidentada historia. 3 Referencias bibliográficas.

Cómo citar: Rial, B. (2017) Los libros impresos para el obispado de Oviedo por Agustín de Paz (1555-1559): un ejemplo de proyecto editorial diocesano durante el Concilio de Trento, en Revista General de Información y Documentación 27 (2), 365-381.

\section{Cristóbal de Rojas y el proyecto editorial oventense}

El obispo de Oviedo Martín Tristán Calvete fallecía en 1546 y ese mismo año, el 8 de octubre, Cristóbal de Rojas y Sandoval era nombrado nuevo obispo de Oviedo. ${ }^{2}$ Cuando el 18 de enero de 1547 Cristóbal de Rojas tomaba posesión del obispado de Oviedo, el panorama litúrgico diocesano ofrecía una situación lamentable en lo que a libros litúrgicos se refiere. El tiempo transcurrido desde la impresión en 1536 de un breviario ovetense por parte del obispo Fernando de Valdés, los problemas derivados de la pobre calidad de esta impresión, y la falta de un manual y misal impresos llevaban al cabildo ovetense a señalar, el 5 de noviembre de 1548, la "necesidad de breviarios, misales y manuales para la diócesis". ${ }^{3}$ Dos años después, el 2 de septiembre de 1550, el cabildo pedía al canónigo Felipe de Ciranes que se reuniese con el provisor para ordenar y preparar un nuevo breviario. ${ }^{4}$ Rojas dejaba Oviedo pocos meses después de este encargo para participar en el Concilio de Trento. La estancia de Rojas en Trento y su participación en el Concilio influyeron sin duda en el proyecto editorial que pondría en marcha tras su regreso a Oviedo. Rojas, como otros obispos castellanos presentes en el Concilio, decidía aplicar las nuevas reglas tridentinas e imbuir su espíritu en su obispado. ${ }^{5}$ Fue probablemente en Trento y en su encuentro con el obispo de Astorga, Pedro de Acuña y Avellaneda, que Rojas percibió la trascendencia de su labor como reformador en Oviedo y la importancia que la publicación de unas reglas precisas y la impresión de libros litúrgicos desempeñaban en dicha reforma. ${ }^{6}$

Tras finalizar la última convocatoria de Trento, el 28 de abril de 1552, Rojas

2 Sobre Cristóbal de Rojas y Sandoval véase por ejemplo García y García, 1984: 459; Fernández Álvarez; Tuero Bertrand; González Novalín, 1977: 198; Gutierrez, 1951: 200-205.

3 El breviario de Fernando de Valdés se acabó de imprimir en Alcalá de Henares el 7 de agosto de 1536 pero la impresión resultó defectuosa "porque la tinta se borraba con el uso y los breviarios perecían". Véase González Novalín, 1968: 92-93; Martín Abad, 1991: 84, 443-444. Existe también una edición incunable del breviario ovetense impresa en Valencia en 1492. Sobre esta edición véase Odriozola, 1996: 223; Serrano Morales, 1898-1899: 504-509. González Novalín afirma que algunos años después del breviario ovetense de 1536 se imprimió también un misal del que no ha quedado noticia. Véase González Novalín, 1968: 93 y Odriozola, 1996: 117.

4 Archivo de la Catedral de Oviedo (en lo sucesivo ACO). Acuerdos Capitulares. Libro 8. Fol. 386R.

5 Cristóbal de Rojas llegaba a Trento el 6 de mayo de 1551 y desarrolló una gran labor sinodal en todas las diocesis por las que pasó. Véase Gutierrez, 1951: 200-205; García y García, 1984: 459.

6 El obispo de Astorga Pedro de Acuña y Avellaneda llegaba a la segunda sesión del Concilio de Trento el 6 de agosto de 1551 participando de manera activa en la redacción de diferentes cánones. Véase Gutierrez, 1951: 885-886. 
posiblemente regresaba a Oviedo con la clara idea de publicar unas constituciones sinodales con las que reglar la vida de su diócesis, y llevar a cabo un importante proyecto editorial con el que reformar el obispado que le había tocado regir. ${ }^{7}$ El 12 de octubre de 1552 el cabildo pedía a "los escritores del breviario", que se había ordenado en 1550, de terminarlo antes de la Navidad de ese mismo año. ${ }^{8}$ El 9 de diciembre el cabildo daba poder a los canónigos Andrés de Solís, Francisco de Santullano, Cristóbal de Avia y Diego Vascones para "acordar las cosas que al dicho cabildo y fábrica de la dicha Santa Iglesia conviene", quizás entre estas cosas, la publicación del breviario y el proyecto editorial que Rojas se proponía realizar. ${ }^{9}$ El 10 de febrero de 1553 el cabildo nombraba a Francisco de Santullano, Fernando de Valdés y Andrés de Carreño "para ver las constituciones que el Señor Obispo ha mandado y quiere hacer" y "comuniquen en el cabildo lo que les parezca y convenga." ${ }^{10}$ Pocas semanas después las constituciones ya estaban listas para su aprobación. El sínodo para refrendarlas daba comienzo el 4 de mayo de 1553 y el 23 de ese mismo mes se publicaban:

Las quales dichas constituciones fueron leydas y publicadas en el dia veintitres de mayo de mill e quinientos e cinquenta y tres años, terminado el synodo que su señoria reverendissima celebro en la sancta iglesia de Oviedo. ${ }^{11}$

Las nuevas constituciones tendrían validez inmediata - aunque se contaría con un plazo de dos meses para interponer alegaciones - y se ordenaba a los arciprestes y clérigos del obispado a llevar una copia, probablemente manuscrita, a sus respectivas parroquias:

Otrosi, mandamos, sancta synodo approbante, que estas constituciones y penas en ellas contenidas liguen y ayan vigor y fuerça desde quatro dias del mes de Mayo deste año de mill e quinientos e cinquenta y tres fasta dos meses primeros siguientes, dentro de los quales mandamos que si alguno se sintiere agraviado dellas, lo venga a allegar ante nos o en nuestra audiencia ante nuestro provisor e vicario general, ca nos estamos prestos de le oyr e hazer aquello que de justicia devamos. E mandamos a los arciprestes y clerigos deste nuestro obispado lleven o hagan llevar unas para cada iglesia parrochial, que esten en ella, y esto a costa de la fabrica de la tal iglesia. ${ }^{12}$

En 1544 se celebraba un nuevo sínodo y, el 9 de abril de 1544, el cabildo mandaba al chantre y a algunos canónigos que viesen "las constituciones que agora se hacen por su señoría para publicar en el sínodo que viene si hay alguna que perjudique". ${ }^{13}$ Es muy plausible que en este sínodo se revisasen y completasen las

7 El obispo Fernando de Valdés había convocado un sínodo en 1533 y 1535 del que emanaron algunas constituciones pero éstas no se imprimieron. Antes de estos sínodos se habían celebrado otros pero parece que tampoco llegaron a imprimirse. Véase García y García, 1984: 454-459.

8 ACO. Acuerdos Capitulares. Libro 8. Fol. 451V.

9 Archivo del Reino de Galicia (en lo sucesivo ARG). Pillado. Mazo 2. Núm. 16. Leg. 418. Sin foliar. Véase Fernández Álvarez, M.; Tuero Bertrand, F.; González Novalín, J. L. Historia de Asturias. Edad Moderna I, Oviedo: Ayalga, 1977: 249.

10 ACO. Acuerdos Capitulares. Libro 8. Fol. 347R. Las constituciones sinodales se solían redactar antes de la reunión sinodal en la cual se aprobaban. Sobre esta cuestión véase, por ejemplo, García y García, 1999: 35.

11 García y García, 1984: 460, 588-589.

12 García y García, 1984: 483.

13 ACO. Acuerdos Capitulares. Libro 8. Fol. 493V. Este sínodo de 1554 no se señala en García y García, 1984. 
constituciones refrendadas en 1553 , bien corrigiendo algunas constituciones en base a las alegaciones recibidas o, por iniciativa de Rojas y el cabildo, echando mano de las que el obispo de Astorga, Pedro de Acuña, había publicado en el sínodo que había celebrado en julio de 1553 y que, en 1554, ya circulaban impresas. ${ }^{14}$ Tomando como modelo las de Astorga, se hacía ahora referencia explícita al espíritu tridentino y a la importancia que los libros litúrgicos y una versión canónica de ellos desempeñaba en la reforma de la vida del obispado. En ellas se ordenaba que todos los clérigos o beneficiados rezasen "cada día las horas canónicas [...] por libro o brebiario", ${ }^{15}$ que todos los sacerdotes celebrasen misa y dijesen "el 'Te igitur' leyéndolo por el libro [misal]", ${ }^{16}$ que todos los oficios fuesen ovetenses, "conformándose con las reglas por nos puestas en nuestro breviario, misal y manual"17 y que, en general, todos los miembros del obispado, tanto seglares como religiosos, guardasen y cumpliesen " lo contenido en los [...] decretos del $[\ldots]$ concilio tridentino"

[...] por quanto en nuestros tiempos ha havido diversos errores y falsas opiniones acerca de nuestra religión cristiana, cuyo auctor principal ha sido Martín Lutero y después otros muchos, sus secuaces, los quales han sembrado tantas y tan diversas heregías en muchas partes de la cristiandad, que ha causado grande escándalo y detrimento entre los fieles cristianos. ${ }^{18}$

Rojas y su cabildo, conscientes de la eficacia de la imprenta en la reforma de su iglesia y en fijar y divulgar un texto canónico para la liturgia y el rezo, en 1555, contrataban con el impresor y librero Agustín de Paz, vecino de Santiago, la impresión de misales y breviarios para su diócesis. El 23 de enero de 1555 el dean Álvaro Valdés, en presencia del provisor Martín Malo y del cabildo, contrataba con Paz la impresión de 1.200 breviarios y 1.100 misales. ${ }^{19}$ Dicha impresión debería

La obligatoriedad de celebrar un sínodo al año ya se señalaba en el siglo VI pero no siempre fue respetada. El Concilio de Trento en su sesión XXIV reiteraba la obligatoriedad de celebrar sínodos diocesanos anuales. Sobre esta cuestión véase, por ejemplo, García y García, 1999: 26; López de Ayala, 1828: 314-315.

14 González Novalín señala que "La existencia de algunas sinodades de otras diócesis en el archivo capitular de Oviedo, compiladas en la primera mitad del siglo XVI, es un indicio del interés que entonces se ponía en reajustar la legislación diocesana de acuerdo con unas directrices más o menos generalizadas." Véase González Novalín, 1968: 84. La misteriosa y debatida coincidencia de las constituciones de Rojas con las publicadas en el sínodo de Astorga celebrado entre el 16 y el 20 de julio de 1553 quizás haya que buscarla en este sínodo de 1554 de Rojas. De este sínodo quizás salió una segunda redacción de las constituciones de 1553 con los pasajes de las de Astorga pero respetando la fecha inicial del primer sínodo. Para un análisis de dichas coincidencias, véase García y García, 1984: 16-19, 460-462. Sobre los problemas que Acuña tuvo con algunos miembros de la iglesia acerca de algunas de sus constituciones, véase Gutierrez, 1951: 885-887.

15 García y García, 1984: 533-534.

16 García y García, 1984: 541. Esta es una copia de una constitución de las de Astorga. Véase García y García, 1984: 137.

17 García y García, 1984: 534. La referencia que se hace en este párrafo a un "Manual” posiblemente se deba a la copia de una constitución de semejante en las de Astorga y no a un manual ovetense del que no aparece ninguna referencia en la documentación. Véase García y García, 1984: 130.

18 García y García, 1984: 475-476. Esta constitución también reproduce una de Astorga. Véase García y García, 1984: 38-39.

19 Desconocemos las razones que movieron al cabildo de Oviedo a considerar a Paz, quien ese mismo año había instalado en Santiago de Compostela su imprenta y librería, como el impresor más idoneo para dicho trabajo. Quizás influyó en la decisión de contratar los servicios de Agustín de Paz el hecho de que éste había impreso para el obispado de Astorga misales y manuales en 1546. Véase Rial Costas, 2007: 111. De los breviarios oventenses, 250 se imprimirían con salterios romanos (50 de éstos en pergamino) y 1.000 con salterios de 
llevarse a cabo en Oviedo pero, dado que el original del brebiario no estaba todavía listo, Paz no estaría obligado a trasladarse a la ciudad hasta que el cabildo lo llamase. Una vez llegado a la ciudad, el cabildo le entregaría a Paz 200 ducados para comprar papel "y traer las otras cosas necesarias, imprenta y oficiales". Paz, por su parte, se comprometía a instalar la imprenta dentro de los cuatro meses siguientes a la entrega de dicho dinero pero, si a su llegada, el original del breviario no estuviese todavía listo, el cabildo le pagaría las costas de su estancia y la de sus oficiales en la ciudad. Por el trabajo de impresión, el cabildo pagaría a Paz cuatro maravedís por cada pliego. Dicho pago se fraccionaría en tres entregas. Al principio de la impresión se le entregarían a Paz 200 ducados-además de los 200 ya entregados inicialmente-, 100 ducados al llegar a la mitad del trabajo, y el resto del dinero dentro de los dos meses siguientes a su finalización:

En el cabildo de la santa ygl[es]ia de Oui[e]do, a veynte y tres dias del mes de hene[ro] de mill e qui[nient]os e çinq[uen]ta e çinco a[ño]s estando los $\mathrm{s}$ [eñore]s del cabildo de la d[ic]ha santa ygl[es]ia ayuntados en su cabildo llamados por campana tanida como lo tienen de vso y de costumbre en vno con el muy rr[everen]do e muy magni[fi]co señor don Alvaro de Valdes, dean de la d[ic]ha santa ygl[es]ia, estando ay $\mathrm{p}$ [re]sente el muy rr[everen]do y muy mag[nifi]co $\mathrm{s}$ [eñ]or dottor M[art]in Malo, can[nonig]o e $\mathrm{p}[\mathrm{ro}$ ]bisor en la d[ic]ha santa ygl[es]ia e ob[is]pado de Oui[e]do, por el muy ill[ustr]e e $\operatorname{rr}[$ everendisi]mo s[eño]r don Xpoval de Rrojas y Sandoval, ob[is]po del d[ic]ho ob[is]pado, en p[re]sençia de mi es[cri]uano y t[estigo]s ynfra es[cri]ptos, fueron conçertados y convenidos de la vna $\mathrm{p}[\operatorname{ar}]$ te los $\mathrm{d}[\mathrm{ic}]$ hos señores $\mathrm{p}[\mathrm{ro}]$ visor, dean y cabildo, por sy y en nombre de la fabrica de la d[ic]ha santa ygl[es]ia, y de la otra Agustin de Paz, ympresor de libros $v[\mathrm{e}] \mathrm{z}[\mathrm{ino}]$ de la çiudad de Santiago questava $\mathrm{p}[\mathrm{re}]$ sente, sobre la ympresion de los briviarios que $\mathrm{p}$ [ar]a este ob[is]pado se an de ymprimir con las condiçiones modos y capitulos sigui[ent]es:

Primeramente quel $\mathrm{d}[\mathrm{ic}]$ ho Agustin de Paz sea obligado de ymprimir en [e]sta çibdad mill e duci[ento]s briviarios deste ob[is]pado de Oui[e]do, çin[cuen]ta mas o menos, en papel de a ochavo el pli[e]go del papel e forma de letra que dexan f[ir]mado el d[ic]ho Agustin de Paz y el d[ic]ho señor p[ro]bisor en poder de mi es[cri]uano. Los doci[ento]s e çinq[uen]ta de los quales bribiarios a de ymprimir con salterios rromanos y los otros rrestantes con salterios desta santa ygl[es]ia como se le dara en el oreginal.

Yten que la letra a de ser de la mesma que queda firmada en poder de mi es[cri]uano, del d[ic]ho señor p[ro]bisor y del d[ic]ho Agustin de Paz. Y a de ser letra nueva y la flor della que no aya travaxado ni p[ar]te della en cosa alg[un]a. Y las antifonas, rresponsos y vsos an de ser de la letra pequeña de glosa a contento de los señores dean y cabildo. Y porque la $\mathrm{d}[\mathrm{ic}]$ ha ympresyon se a de hazer nesta çiudad a de ser la forma con el num[er]o de rrenglones o p[ar]tes segund y como a

Oviedo. Véase Rial Costas, 2007: 118. El numero de ejemplares correspondía probablemente con el de sacerdotes pues concuerda con el número de breviarios impresos para Valdés en 1536 y con el número de parroquias que Aponte de Quiñones señalaba en 1594 en el obispado de Oviedo. Véase Fernández Álvarez;

Tuero Bertrand; González Novalín, 1977: 213. 
los $\mathrm{d}[\mathrm{ic}]$ hos señores $\mathrm{p}$ [ro]bisor, dean y cabildo, ha las $\mathrm{p}$ [er] sonas que $\mathrm{p}$ [ar]a ello deputaren paresçiere como fuere su boluntad. Y quel rruvio de los d[ic]hos briviarios a de ser de muy buen v[er]mellon vien colorado limpio claro a contento de los d[ic]hos señores.

Yten quel d[ic]ho Agustin de Paz sea obligado a ymprimir en la primer[a] pagina de cada briviario las armas del señor $o b[i s]$ po con su capillo e orla a su costa. Y si los d[ic]hos s[eñore]s p[ro]bisor, dean y cavildo quisieren que lleve algu[na]s otras figuras o ystorias, se corten y hagan a costa de la obra y no del d[ic]ho Agustin de Paz.

Yten quel d[ic]ho Agustin de Paz no pueda ymprimyr ni vender ningun briviario deste $\mathrm{ob}$ [is]pado syn liçençia de los $\mathrm{d}[\mathrm{ic}]$ hos señores $\mathrm{p}$ [ro]bisor, dean y cabildo mas de los $\mathrm{d}[\mathrm{ic}]$ hos mill y doçi[ento]s, çinq[uen]ta mas o menos, sopena de çien $\mathrm{d}$ [ucado]s por cada bribiario que ymprimiere o vendiere aplicados a la fabrica desta santa ygl[es]ia de Oui[e]do.

Yten que por quanto el oreg[in]al del d[ic]ho bribiario no esta acauado de corregir escrevir y poner en $\mathrm{p}$ [er]feçion, ny se save de çierto $\mathrm{p}$ [ar]a quando lo estara, quel d[ic]ho Agustin de Paz no sea obligado a venir ni venga a entender en la $\mathrm{d}[\mathrm{ic}]$ ha obra hasta que los $\mathrm{d}[\mathrm{ic}]$ hos señores le ynvien a llamar que venga. Y que entonçes sea obligado a venir a esta çiudad dentro de vn mes desde el dia que fuere llamado. Y benido, los d[ic]hos señores le ayan de dar y den doçi[ent]os d[ucado]s $\mathrm{p}$ [ar]a comprar papel y traer las otras cosas neçesarias, emplenta y ofiçiales a esta çiudad. Lo qual todo traya e asiente en ella dentro de q[ua]t[r]o meses despues que asi rreçebiere los $\mathrm{d}[\mathrm{ic}]$ hos din[er]os. Por los quales quando los rreçeviere aya de dar e de fianças e seguridad a los $\mathrm{d}[\mathrm{ic}]$ hos señores $\mathrm{q}[\mathrm{ue}]$ no compliendo de su p[ar]te como d[ic]ho hes los bolveran e pagaran los daños y costas que por no lo complir se les rrecreçieren.

Yten que los $\mathrm{d}[\mathrm{ic}]$ hos señores $\mathrm{p}$ [ro]bisor, dean y cabildo ayan de dar y den al $\mathrm{d}[\mathrm{ic}]$ ho Agustin de Paz, p[ar]a quando truxere la d[ic]ha emprenta e aparejo e ofiçiales, casa en esta çibdad en que viba y este la $\mathrm{d}[\mathrm{ic}] \mathrm{ha}$ emprenta a costa de la $\mathrm{d}[\mathrm{ic}] \mathrm{ha}$ obra. E ayan de dar y den a su costa corretor o corretores que la vean corrixan y esaminen ansy en la ortografia como en la horden y todo lo demas que forme la muestra de cada pli[e]go conforme a la qual dandola el d[ic]ho Agustín de Paz ympresa cumpla e satisfaga e q[ue] no alçara mano de la obra hasta darla perfeta y acauada.

Yten que si trayda y asentada la d[ic]ha emprenta en esta çiudad por no le dar rrecado del oreginal holgare, se le pague cada dia por los $\mathrm{d}[\mathrm{ic}]$ hos señores lo qu[e] el y sus ofiçiales les hizieren de costa.

Yten quel d[ic]ho Agustin de Paz a de ymprimir y dar ympresos en esta çiudad como d[ic]ho hes los d[ic]hos briviarios a quatro $\mathrm{m}[\mathrm{a}] \mathrm{r}[$ avedi]s cada pli[e]go de toda costa $\mathrm{p}[\mathrm{ar}] \mathrm{a}$ en pago de lo qual los $\mathrm{d}[\mathrm{ic}]$ hos señores $\mathrm{p}[\mathrm{r}]$ obisor, dean y cabildo le daran al prinçipio de la obra otros doc[iento]s d[ucado]s, y en medio della otros çien $\mathrm{d}[$ ucado]s, y todo lo rrestante al $\mathrm{d}[\mathrm{ic}]$ ho fin de la obra dentro de dos meses despues de acauada. Y que si a culpa del d[ic]ho Agustin de Paz y de sus aparejos y ofiçiales algund pli[e]go o pli[e]gos della fuere herrado y no conforme a la d[ic]ha muestra y condiçiones, el d[ic]ho Agustin de Paz a su costa sea obligado a los 
tornar a ymprimir y dar hechos segund y como arriva se in[dica] y es obligado. Y si a cavsa del $\mathrm{d}[\mathrm{ic}]$ ho oreginal o por culpa o nigligençia del $\mathrm{d}[\mathrm{ic}]$ ho corretor o corretores acontesçiere el $\mathrm{d}[\mathrm{ic}]$ ho yierro sea a cargo de los $\mathrm{d}[\mathrm{ic}]$ hos señores y se obieren de tornar a emprimir sea a su costa y de la d[ic]ha obra.

Yten quel d[ic]ho Agustin de Paz aya de haçer y haga asi mismo misales deste $\mathrm{ob}$ [is]pado conforme al oreg[in]al que p[ar]a ello se le diere. Sea la letra de vna muestra que queda ansi mismo f[ir]mada del d[ic]ho señor $\mathrm{p}[$ ro]bisor y del $\mathrm{d}[\mathrm{ic}]$ ho Agustin de Paz al mesmo preçio de a q[ua]t[r]o m[a]r[avedi]s cada pli[e]go. Deva ser conforme a los mesmos modos y condiçiones y el papel. La marca del papel a de ser a contento de los $\mathrm{d}[\mathrm{ic}]$ hos señores. Y los misales sean hasta mill e çiento en num[er]o.

Yten que quando los $\mathrm{d}[\mathrm{ic}]$ hos señores enviaren llamar al d[ic]ho Agustin de Paz, que venga a entender en la d[ic]ha obra e rreçevir los din[ero]s, envien a su casa a la çiudad de Sant[iag]o. E que no veniendo o enviando poder vastante a rreçebir los din[ero]s como d[ic]ho hes dentro del d[ic]ho termi[n]o, los d[ic]hos señores puedan contratar libremente con otro $[\ldots] .{ }^{20}$

\section{Agustín de Paz en Oviedo y su accidentada historia}

Paz regresaba a Santiago inmediatamente después de firmar el acuerdo pero algunos meses después, a pesar de no estar todavía listo el original del breviario, el cabildo lo llamaba de nuevo a Oviedo. El 24 de mayo de 1555 Paz todavía estaba en Santiago, tomando a Gregorio Domínguez como aprendiz de librero, encuadernador y componedor, sin duda a raiz de su inminente marcha a Oviedo. ${ }^{21}$ Dos semanas después Paz ya estaba en Oviedo, habiendo dejado a su familia y criado a cargo de su imprenta y librería de Santiago. El 5 de junio de 1555, Cristóbal de Avia y Andrés Carreño le hacían entrega de los primeros 200 ducados:

En la çiudad de Ouiedo a çinco dias del mes de junio de mill e qui[nient]os e cinq[uen]ta e çinco a[ño]s, ante mi el escriuano y t[estigo]s ynfra es[cri]ptos paresçieron pr[e]sentes los señores Xpoval de Auia, en nombre e por comision de los muy magni[fi]cos señores Dottor M[art]in Malo, can[onig]o y p[ro]bisor desta santa ygl[es]ia y ob[is]pado de Oui[e]do, por el muy ill[ustr]e e rr[everendisi]mo señor don Xpoval de Rrojas e Sandobal, ob[is]po del d[ic]ho ob[is]pado, e del dean y cabildo de la d[ic]ha santa igl[es]ia y dixeron que, por quanto los d[ic]hos se[ñore]s $\mathrm{p}$ [resen]tes en veynte y tres dias del mes de hen[ero] p[ro]ximo(sic) pasado, ante mi es[cri]uano, avian capitulado y asentado en nombre de la fabrica de la d[ic]ha santa igl[es]ia como Agustin de Paz, ympresor de libros, que ympremiese en [e]sta çibdad mill e doc[ient]os [breviarios] deste ob[is]pado en çierta forma e condiçiones, segu[n]d se avia otorgado entre ellos. Entre los quales hera vna que veniendo el $\mathrm{d}[\mathrm{ic}]$ ho Agustin de Paz a esta çiudad por mand[ad]o de los d[ic]hos señores, ellos le davan doci[ent]os $\mathrm{d}$ [ucado]s $\mathrm{p}$ [ar]a comprar papel e traer las otras cosas neçesarias de

ARG. Real Audiencia de Galicia. Expedientes. Caja 418/16. Sin foliar.

21 Archivo Histórico Universitario de Santiago (en lo sucesivo AHUS). Protocolos Notariales de Santiago.

Protocolo número 312. Fol. 94R. Véase Rial Costas, 2007: 82. 
enprenta e ofiçiales a esta çiudad p[ar]a lo asentar en [e]lla dentro de q[ua]t[r]o meses despues que ansi rreçeviese los $\mathrm{d}[\mathrm{ic}]$ hos $\operatorname{din}[\mathrm{ero}] \mathrm{s}$. Y por quando agora el $\mathrm{d}[\mathrm{ic}]$ ho Agustin de Paz hera venido y estava $\mathrm{p}[\mathrm{re}]$ sente $\mathrm{p}$ [ar]a los rreçivir, ellos en nombre de los d[ic]hos sus $\mathrm{p}[\operatorname{art}] \mathrm{es}$ e[n] complimi[ent]o del $\mathrm{d}[\mathrm{ic}]$ ho contrato e capitulaçion, le pedian y rrequerian los rreçiva y les de fianças y seguridad q[ue] no cumpliendo de su $\mathrm{p}$ [ar]te lo q[ue] asi tiene capitulado y otorgado çerca dela ympresion de los $\mathrm{d}[\mathrm{ic}] \mathrm{hos}$ bribiarios, se los bolvera e rrestituyra con los cost[e]s y danos que por no lo compense les rrecreçiere el d[ic]ho Agustin de Paz, que como $\mathrm{d}[\mathrm{ic}]$ ho hes estava $\mathrm{p}[\mathrm{re}]$ sente, quel avia venido a rreçivir los $\mathrm{d}[\mathrm{ic}]$ hos dineros $\mathrm{p}$ [ar]a traer el papel e aparejo de la d[ic]ha ymp[re]sion a esta çiudad questava presto de lo rreçevir y dar luego por ellos las fianças y seguridad vastante como estava obligado. E luego los d[ic]hos señores Xpoval de Auia e Andres de Carreño, en nombre de los $\mathrm{d}[\mathrm{ic}]$ hos sus $\mathrm{p}[\mathrm{ar}] \mathrm{tes}$, le dieron rrealmente y entregaron los d[ic]hos d[o]ci[ent]os $\mathrm{d}[$ ucado]s en rr[ea]les. Y el d[ic]ho Agustin de Paz los rreçevio en presençia de mi el es[cri]uano y de los t[estigo]s ynfra es[cri]ptos e se dio por vien contento pagado e satis[fe]cho dellos [....$^{22}$

El original del breviario no estaba todavía listo y fue probablemente en torno a estas fechas que Rojas y su cabildo decidieron imprimir las constituciones del sínodo de 1553. La larga demora que estaba sufriendo el breviario, la consiguiente inactividad de Paz y, posiblemente, el pobre resultado que las nuevas reglas sinodales estaban teniendo en el clero ovetense, dada su deficiente difusión manuscrita, influyeron sin duda en esta decisión. ${ }^{23}$ El 5 de julio de 1555 el cabildo pedía a Andrés Carreño que le entreguase a Paz 250 ducados más "para comprar papel para la impresión de los dichos misales y briuiarios" y también "papel para las constituciones". ${ }^{24}$ Paz viajaba a Francia, probablemente a Toulouse, con dicho dinero y allí compraba una nueva prensa y algún material, contrataba oficiales, adquiría alguna partida de libros con los que abrir un nuevo negocio de librería en Oviedo $\mathrm{y}$, con un salvoconducto que el cabildo ovetense había solicitado, encargaba en el país vecino una importante partida de papel. ${ }^{25}$

22 ARG. Real Audiencia de Galicia. Expedientes. Caja 418/16. Sin foliar. Véase Rial Costas, 2007: 119.

23 Todo indica que la impresión de las constituciones sinodales de Rojas no estuvo inicialmente prevista pues dicho encargo no se menciona en el contrato. Es sin embargo curioso que las constituciones de Rojas abrevian y adaptan el pasaje que a este respecto contienen las de Astoga. Las constituciones de Astorga de 1553 dicen: "Otrosi, mandamos, sancta synodo approbante, a los arciprestes y clerigos de todos los arciprestazgos de nuestro obispado que, hasta seys meses primeros siguientes del día de la publicacion de estas constituciones saque cada uno para sus yglesias unas constituciones a costa de las fabricas, y esten en cada yglesia parrochial $\mathrm{o}$ anexa que por si tenga clerico, con su cadena de hierro, en parte conveniente. Y trayanse primero ante nos o ante nuestro provisor para que sean vistas y corregidas". Las constituciones de Rojas reducen este pasaje a "E mandamos a los aciprestes y clerigos deste nuestro obispado lleven o hagan llevar unas para cada iglesia parrochial, que estén en ella, y esto a costa de la fábrica de la tal iglesia.” García y García, 1984: 45, 483.

24 ARG.Real Audiencia de Galicia. Expedientes. Caja 418/16. Sin foliar. Los 50 ducados restantes quizás eran los dineros que, como se mencionaba en el contrato, el cabildo se había comprometido a entregar a Paz por la demora en el inicio de los trabajos de impresión.

25 Paz parece adquirir en Francia un nuevo tipo redondo y algunas capitulares y grabados. El cabildo ovetense había solicitado un salvoconducto al Gobernador de Fuenterrabía para poder traer de Francia "cincuenta balas de papel a descargar en uno de los puertos de Asturias"ARG. Real Audiencia de Galicia. Expedientes. Caja 418/16. Sin foliar. Se hace referencia a dicho salvoconducto en la demanda que el cabildo ovetense interpone para recuperar los materias de Agustín de Paz. Véase más adelante. En dicha demanda, Jerónimo Peligrín, vecino y estante en Oviedo de edad de 26 o 27 años, declara que "el dicho Agustín de Paz topó con este 
Pero los problemas para el proyecto editorial de Rojas, los retrasos en los trabajos de impresión y las continuas entregas de dinero no contempladas en el contrato no habían hecho más que empezar. Al final de 1555 el original del breviario no estaba todavía listo y Paz, tras su regreso a Oviedo, aprovechaba esta inactividad para realizar algunos trabajos propios y solicitaba nuevas entregas de dinero. ${ }^{26}$ - El 16 de diciembre de 1555 el cabildo todavía pedía al maestro Ninez, a Felipe de Zarauz y a Pedro Suárez ser los correctores del breviario. ${ }^{27}$ El 21 de diciembre de 1555 se le entregaban a Paz otros 50 ducados "a cuenta de los dineros que tiene recibidos para los misales", y el 30 de diciembre otros 50 ducados más. ${ }^{28}$

En torno a los últimos días de 1555 o primeros de 1556, Paz comenzaba la impresión de las constituciones sinodales de Rojas. El 4 de enero de 1556 el cabildo ordenaba al canónigo y administrador de la fábrica, Andrés Carreño, que le entregase a Paz 150 ducados "allende los otros cincuenta ducados que le dió cuando vino a esta ciudad":

[En el margen:] Man[damien]to administrador breviarios

Mandaron al s[eñor] can[oni]go Carreño q[ue], de los m[a]r[avedi]s q[ue] [e]l $\mathrm{s}$ [eñ]or ob[is]po dexo de los missales, de a Agustin de Paz, impresor del breviario, çiento y çinq[uen]ta ducados allende los otros çinq[uen]ta d[ucad]os q[ue] le dio quando vino a esta çibdad. Y mandaronle dar para ello libra[mien]to. P[re]sente el $\mathrm{s}[\mathrm{eñ}]$ or maestro Ninez, provisor. ${ }^{29}$

El 7 de febrero de 1556 se le pagaban a Paz los dichos 150 ducados que, con los "otros cincuenta ducados que le dieron quando vino aqui", completaban otros 200, quizás por la impresión de las constituciones. ${ }^{30}$ El 25 de marzo Andrés Carreño le entregaba a Paz 500 reales "de los dineros que tiene de los misales" para traer pergaminos para la encuadernación de las constituciones. ${ }^{31}$ El 12 de abril de 1556 Paz terminaba de imprimir las constituciones, entregándolas encuadernadas en los meses siguientes y, con el original de breviario ya listo, comenzaba a trabajar en él. ${ }^{32}$

En 1556, mientras Paz trabajaba ya en la impresión de los breviarios, Rojas

testigo en Tolosa de Francia y le trajo a esta ciudad para encuadernar las dichas obras". ARG. Real Audiencia de Galicia. Expedientes. Caja 418/16. Sin foliar. Un sencillo cálculo permite observar que los 250.000 pliegos que componen 50 balas de papel solo serían suficientes para imprimir los breviarios y misales. El papel de las constituciones, de menor calidad, quizás se adquirió en Castilla.

26 Durante este tiempo, mientras esperaba todavía el texto del breviario o algún otro encargo por parte del cabildo, Paz imprimía unos nuevos preliminares en romana de dos obras que había impreso en 1550 en Mondoñedo y algunos formularios de cartas de obligación y poder para notarios. Para una cronología distinta véase Odriozola, 1974: 252; Cabano, 1995: 438-439.

27 ACO. Acuerdos Capitulares. Libro 8. Fol. 536R.

28 ARG. Real Audiencia de Galicia. Expedientes. Caja 418/16. Sin foliar.

29 ACO. Acuerdos Capitulares. Libro 8. Fol. 538V.

30 Ese mismo día también se le entregaban "dos ducados para la comida de los oficiales". ARG. Pillado. Mazo 2. Núm. 16. Leg. 418. Sin foliar.

31 ACO. Acuerdos Capitulares. Libro 8. Fol. 543V; ARG. Real Audiencia de Galicia. Expedientes. Caja $418 / 16$. Sin foliar.

32 García y García, 1984: 589. Un análisis del único ejemplar conocido de las Constituciones sinodales de Oviedo de 1553 y su reproducción facsimilar en Constituciones sinodales del obispado de Oviedo de 1553, Oviedo: Biblioteca Antigua Asturiana, 1981. Introducción y estudio preliminar de José Luis Pérez de Castro. Desconocemos la cantidad de constituciones que se imprimieron pero, si suponemos que los 400 ducados entregados a Paz en 1555 y 1556 fueron por el pago de las Constituciones y que cada pliego impreso fue pagado a 4 maravedís como los breviarios y misales, la impresión debió estar en torno a 1200 ejemplares. 
dejaba Oviedo para trasladarse como obispo a la diócesis de Badajoz. E1 4 de mayo de 1556 Rojas era nombrado obispo de Badajoz y, ese mismo día en Santiago, Álvaro Moniz le reclamaba a Paz saldar una deuda de 85.000 maravedís que éste había contraido con su padre en Astorga en $1548 .{ }^{33}$ No sabemos cómo se resolvió dicha reclamación pero, en cualquier caso, el cabildo ovetense siguió adelantando dinero a Paz. El 10 de junio de 1556 se le entregaban a Paz 50 ducados "los quales son para comprar papel para la imprenta de misales y breviarios" y, el 27 de junio, 100 ducados más. ${ }^{34}$ Rojas dejaba Oviedo sin ver cumplido su proyecto editorial y Jerónimo de Velasco (1556-1566), otro hombre con experiencia tridentina, tomaba posesión del obispado ovetense el 4 de julio de ese mismo año con el breviario de Rojas todavía sin acabar. ${ }^{35}$ El proyecto editorial de Rojas seguiría adelante con Velasco, pero también lo harían los adelantos de dinero y problemas con Paz. En diciembre de 1556, ya estaba impreso el breviario y el 9 de diciembre de $1556 \mathrm{Paz}$ hacía una nueva petición al cabildo "tocante a la impresión que había hecho de los breviarios y la que había de hacer de los misales". ${ }^{36}$ Paz pedía de nuevo dinero. Pocos días después, el 15 de diciembre, se le libraban 50 ducados "por papel e impresión de misales y breviarios" y otros 70 ducados por "lo que se le debe de la impresión de los breviarios". ${ }^{37}$-Al día siguiente, el 16 de diciembre, el cabildo recibía carta de pago de los 170 ducados que el canónigo Andrés Carreño había entregado algún tiempo atrás a Paz, y encargaban al arcediano de Villaviciosa y a Pedro de Ávia que contratasen la encuadernación de los breviarios con él:

[En el margen:] Libr[amien]to impresor

Por quanto el s[eñ]or canonigo Andres de Carreño avia pagado a Agustin de Paz impresor çiento y setenta d[ucad]os sin lib[ramien]to para en q[uen]ta de los breviarios, dixeron $\mathrm{q}[\mathrm{ue}]$ los savia[n] por bien pagados con la carta de pago del $\mathrm{d}[\mathrm{ic}]$ ho Agustin de Paz, t[estig]os los d[ic]hos. ${ }^{38}$

[En el margen:] Enquadernar breviarios

Mandaron al s[eño]r ar[cediano]o de Villav[icios]a y P[edr]o de Avya q[ue] contraten y asienten con Agustin de Paz la enquadernaçion de los breviarios en sus nombres. ${ }^{39}$

Dos meses más tarde, el 4 de febrero de 1557, los breviarios encuadernados eran entregados al cabildo, y éste le pedía a los canónigos Pedro de Avia y Juan de la Ribera que los repasasen para asegurarse que no hubiese "faltas, vicios y defectos [...] , así en el orden como en la latinidad":

Cometieron sus $\mathrm{m}$ [erced]es a los s[eñore]s P[edr]o de Auya e Juan de la Ribera, canonigos, $\mathrm{q}[\mathrm{ue}]$ ven el breviario nuevo q[ue] agora se a ymprimido aqui en [e]sta çibdad, q[ue] repasen e noten todas las faltas, viçios e defettos q[ue] les paresçiere $\mathrm{q}[\mathrm{ue}]$ tiene, asi en la horden como en la latinidad e todo lo demas, e q[ue] les

\footnotetext{
33 AHUS. Protocolos Notariales de Santiago. Protocolo número S-123, Fol. 120R.

34 ARG. Real Audiencia de Galicia. Expedientes. Caja 418/16. Sin foliar.

35 Sobre Jerónimo de Velasco véase, por ejemplo, García y García, 1984: 459; Fernández Álvarez; Tuero Bertrand; González Novalín, 1977: 200-201; Flórez, 1795: 127-128.

36 ACO. Acuerdos Capitulares. Libro 8. Fol. 568R.

37 ARG. Real Audiencia de Galicia. Expedientes. Caja 418/16. Sin foliar.

38 ACO. Acuerdos Capitulares. Libro 8. Fol. 568V.

39 ACO. Acuerdos Capitulares. Libro 8. Fol. 568V.
} 
cuenten y ayan por presentes el tiempo q[ue] se ocuparen en ello. ${ }^{40}$

El 6 de febrero de 1557 Agustín de Paz, al no estar todavía listo el original del misal, hacía una nueva petición al cabildo "para entretanto hazer otra obra" y éste decidía que los canónigos Juan de Mayorga y Diego de Salazar le entregasen a Paz otros 150 ducados "de los casos que son a su cargo, y concedió el señor obispo don Cristóbal de Rojas":

[En el margen:] Librami[ent]o impressor

Por quanto Agostin de Paz pedia el original del missal y porque no estava acabado pedia $\mathrm{q}[\mathrm{ue}] \mathrm{le}$ diesen algunos dineros para entretanto hazer otra obra. Mandaron que se le diese vn libram[ient]o para [que] el can[onig]o Juan de Mayorga e Diego de Salazar le diesen çiento y çinq[uen]ta ducados de los casos q[ue] son a su cargo e conçedio el s[eñ]or ob[is]po don Xpobal de Rojas. ${ }^{41}$

El nuevo trabajo que Paz se disponía a hacer era probablemente la impresión de unas bulas de los "casos reservados" que Rojas había encargado publicar y vender en el obispado para recaudar fondos para su proyecto. ${ }^{42}$ Estas bulas se distribuyeron en el obispado ovetense durante los meses siguientes bajo la responabilidad de Diego de Salazar y con los pingües beneficios de su venta se comenzaría a costear el misal. El 14 de febrero de 1557 el canónigo Andrés Carreño entregaba a Paz otros 95.000 maravedís. ${ }^{43}$ El 4 de marzo Paz recibía los 150 ducados que había solicitado en febrero y, el $3 \overline{0}$ de ese mismo mes, el cabildo ordenaba que se le entreguasen a Carreño 72.500 maravedís por el dinero que había entregado a Paz el 14 de febrero "para en quenta de ciertas costas y gastos que hizo de los dichos casos": 44

[En el margen:] Libram[ient]o Agustin de Paz

Por quanto el s[eñ]or can[onig]o Andres de Carreño avia dado, en las quentas $\mathrm{q}[\mathrm{ue}]$ le tomaron de los casos q[ue] avia pagado a Agostin de Paz, çiertos ducados y para en quenta de çiertas costas y gastos $\mathrm{q}[\mathrm{ue}]$ hizo de los $\mathrm{d}[\mathrm{ic}]$ hos casos y por quanto se le devia de esto sesenta y dos mill y q[ui]n[ient]os m[a]r[avedi]s, mandaron $\mathrm{q}[\mathrm{ue}]$ le disen vn librami[ent]o para $\mathrm{q}[\mathrm{ue}]$ se los pagasen el can[onig]o Juan de Mayorga o D[ie]go de Salazar, reçeptores de los d[ic]hos casos, de la d[i]cha hazienda. ${ }^{45}$

40 ACO. Acuerdos Capitulares. Libro 8. Fol. 571R-V.

41 ACO. Acuerdos Capitulares. Libro 8. Fol. 572R.

42 No se tiene noticia de ningún ejemplar de este tipo de bulas de los casos reservados. Solo José Goñi Gaztambide aporta dos breves pero importantes noticias acerca de ellas: "Asimismo el cardenal prometió ceder al rey sus casos y declaró que si se pedían a los demás obispos los suyos, se recaudaría tanto dinero como con la Cruzada, pero en opinión de la princesa, la absolución de los casos reservados a los obispos era muy poco productiva y si fuese como el cardenal pretendía, el papa la atajaría." "El 6 septiembre 1568 el Nuncio en Madrid, Juan Bautista Castagna, juzgó conveniente poner en conocimiento del papa un hecho que le causó mala impresión. Varios obispos españoles habían impreso unas buletas, en las que se concedía varias gracias, entre ellas la de poder ser absueltos de los casos reservados al Ordinario, a los que tomando una de dichas cédulas dieran cierta limosna tasada con destino a determinadas obras pías. Según ellos, se trataba de un derecho usado muchas veces y que en justicia no se les podía quitar. Castagna, además de dar aviso de este suceso al papa y remitirle varios ejemplares de las buletas, se quejó de ello ante el rey, el Cardenal de Sigüenza y el obispo de Cuenca, y la cosa cesó.” Goñi Gaztambide,1958: 541, 586.

43 ARG. Real Audiencia de Galicia. Expedientes. Caja 418/16. Sin foliar.

44 ARG. Real Audiencia de Galicia. Expedientes. Caja 418/16. Sin foliar.

45 ACO. Acuerdos Capitulares. Libro 8. Fol. 573V. 
Ese mismo día, el 30 de marzo de 1557, el cabildo ordenaba a Diego de Salazar que entregase a Paz "de los maravedís de los casos" el dinero necesario para pagar el alquiler de su casa en Oviedo:

Señor th[e]s[orer]o Diego de Salazar, prioste, los señores dean y cabildo de la santa igl[es]ia de Oui[e]do mandan que de los $\mathrm{m}[\mathrm{a}] \mathrm{r}[$ avedi]s de los casos que son a su cargo pague Agustin de Paz, ympresor, el arrendamiento de la casa del año pasado que quedaron de darle q[ue] con conoçimi[ent[ent]o de la paga se los tomaran en quenta. Fecho en [e]l cabildo, a último de março de mill e qui[nient]os e çinq[uen]ta e siete años. Pedro de Auia.

Yo Agustin de Paz, ympresor, soy contento y pagado de bos, Diego de Salazar, prioste, del arrendami[ent]o de la casa que more del señor Diego de Hevia y su hijo y nuera. La qual casa more vn año e çinco meses en rraçon de catorze d[ucado]s cad[a] año. Son diez y ocho d[ucado]s quatro rr[eale]s los quales se pagaron al $\mathrm{d}[\mathrm{ic}]$ ho Diego de Hevia y sus hijos y dellos doy carta de o[bli]g[aci]o[n] al d[ic]ho Diego de Salazar $\mathrm{p}$ [ar]a que se los tomen en quenta conforme a este librami[ent]o rretro es[cri]pto. Fecho en Oui[e]do a vltimo de jullio de mill e qui[nient]os e çinq[uen]ta siete a[ño]s, Agustín de Paz. ${ }^{46}$

En torno a esas mismas fechas se le entregaba a Paz el original del misal y en julio de 1557 ya estaba trabajando en él. El 23 de julio el cabildo ordenaba al licenciado Valiña y al provisor que le entreguasen a Paz, quien "entendía en la impresión de los misales", 300 ducados "de los dineros de los casos" y cuatro ducados que le debía a sus oficiales:

[En el margen:] Libram[ient]o impressor

Por quanto Agostin de Paz, impresor, entendia en la impression de los missales y se le avian de dar dineros, acordaron y mandaron juntamente con el s[eñ]or lic[encia]do Vallina y provisor q[ue] le diesen tresçientos ducados de los dineros de los casos y [...] y mas q[ue] le de[n] q[ua]tro d[ucad]os del comienço del missal y fin del breviario q[ue] le deve a los ofiçiales de la emprenta. ${ }^{47}$

El 25 de octubre el cabildo ordenaba a Diego de Salazar que adelantase a Paz otros 300 ducados más "de los dineros que tiene de los casos", "tomando de él fianzas bastantes" de que cumpliría con lo contratado:

[En el margen:] Librami[ent]o

E mandaron $\mathrm{q}[\mathrm{ue}]$ el thesoro $\mathrm{D}$ [ieg]o de Salazar, de los dineros $\mathrm{q}[\mathrm{ue}]$ tiene de los casos, de a Agostin de Paz, impresor, tresçientos d[ucad]os a q[uen]ta de los missales, tomando d[e] el fianças bastantes $\mathrm{q}[\mathrm{ue}]$ complira con este contrato. $\mathrm{Y}$ ansi mesmo q[ue] pag[u]e al s[eñ]or c[anoni]go Xpoual de Avia diez y siete mill $\mathrm{m}[\mathrm{a}] \mathrm{r}$ [avedi]s y al dottor Malos ocho mill y q[ui]ni[ent]os r[eal]es q[ue] hobieren de aver por las constituçiones. Y mandaronles dar libram[ient]o lo que mando juntamente al s[eñ]or liçen[cia]do Valliño, provisor, presente. ${ }^{48}$

El 3 de diciembre de 1557, Diego de Salazar entregaba a Paz los 300 ducados "a

\footnotetext{
46 ARG. Real Audiencia de Galicia. Expedientes. Caja 418/16. Sin foliar.

47 ACO. Acuerdos Capitulares. Libro 8. Fol. 582V. También en ARG. Real Audiencia de Galicia. Expedientes. Caja 418/16. Sin foliar.

48 ACO. Acuerdos Capitulares. Libro 8. Fol. 592R.
} 
cuenta de los misales" que el cabildo había concedido a Paz en octubre. ${ }^{49}$ Durante los primeros meses de 1558, Paz seguiría trabajando en la impresión de los misales pero, en abril de ese mismo año, con tan solo una tercera parte del misal impreso, Paz era reclamado por la justicia por "hacer y meter en estos reinos bulas de Cruzada y de Composición y de Santiago falsas", trasladado de Oviedo a Santiago, preso con su componedor Florín y Alonso García Tinajas, recaudador de la bula de la Cruzada en Galicia, el trabajo del misal paralizado, y su imprenta y librería secuestradas. ${ }^{50} \mathrm{El}$ cabildo de Oviedo se opuso inmediatamente a dicho secuestro e intentó recuperar el material de Paz, alegando que éste se había comprado con el dinero del cabildo y que por lo tanto era de su propiedad. ${ }^{51}$-El cabildo ovetense nombraba a Rodrigo Fernández da Pena como su procurador en la causa para reclamar sus derechos sobre los pliegos del misal impresos, la imprenta, el salvoconducto para la compra de papel en Francia, y todo el material necesario para la impresión, y poder reanudar así la impresión de los misales: ${ }^{52}$

Rodrigo Fernandez da Pena, en nombre del dean e cavildo de la ygl[es]ia catedral de Oviedo, se opone al se[cues]tro hecho en los b[ien]es de Agustin de Paz e pide q[ue] Agustín de Paz jure e declare al thenor desta pet[ici]on [...]

Rrodrigo Fernandez da Pena, en nombre e como $\mathrm{p}$ [rocurado]r que soi del dean e cabildo de la yg[es]lia catedral de Obiedo, digo q[ue] los d[ic]hos mis partes se conçertaron con Agostin de Paz, ympresor, q[ue] al presente esta preso en la carçel rreal, les ymprimiese los brebiarios e misales y otras cosas de la d[ic]ha ygl[es]ia de Obiedo. Y los d[ic]hos dean y cabildo vbieron salboconduto para que se podiese traer e truxiese el papel para la tal ympresión de Françia. E dieron y entregaron el $\mathrm{d}[\mathrm{ic}]$ ho salboconduto al d[ic]ho Agostín de Paz. Y le dieron y entregaron çierta quantidad de dineros de la fabrica de la d[ic]ha ygl[es]ia para comprar la emprenta y el papel y los aparejos de la emprenta, con los quales dineros el d[ic]ho Agostin de Paz compro la emprenta y los aparejos della y el papel. Y abiendo el d[ic]ho Agostin de Paz començado a empremir los d[ic]hos libros, le prendio el liçençiado Colmenares, oydor que fue deste rreino, y le tomo el salboconducto que los $\mathrm{d}[\mathrm{ic}] \mathrm{hos}$ mis partes tenian para poder traer de Françia el papel para la d[ich]a ympresion y secuesto. Y embargo la d[ic]ha emprenta y aparejos della y lo q[ue] estaba ymp[re]so y el papel q[ue] se abia traydo para la d[ic]ha ympresión. El qual secuesto no puede azer ni poner pues la d[ic]ha ymprenta y aparejos della se compraron con los dineros quel d[ic]ho Agostin de Paz resçibio de los d[ic]hos mis partes [roto] pel q[ue] estaba ympreso y por emprimir q[ue] fue secuestrado se traxo para em[roto] los brebiarios y misales y otras cosas de la d[ic]ha ygl[es]ia y obispado y se co[roto] los dineros de los $\mathrm{d}[$ ic] hos mis partes y se debe mandar entregar a 1[roto] partes la d[ic]ha emprenta con sus aparejos y el d[ic]ho papel y lo que es [roto] pues se compró con los dineros que los $\mathrm{d}$ [ic]hos mis partes dier[roto] tin de Paz mayormente para q[ue] el d[ic]ho Agostin de Paz not[roto] los dineros

49 ARG. Real Audiencia de Galicia. Expedientes. Caja 418/16. Sin foliar. Esta es la última entrega de dinero que el cabildo de Oviedo hace a Agustín de Paz de la que tenemos noticia. ARG. Real Audiencia de Galicia. Expedientes. Caja 418/16. Sin foliar. ARG. Real Audiencia de Galicia. Expedientes. Caja 418/16. Sin foliar. ARG. Real Audiencia de Galicia. Expedientes. Caja 418/16. Sin foliar. 
$\mathrm{q}[\mathrm{ue}]$ rresçibio de los $\mathrm{d}[\mathrm{ic}]$ hos mis partes. $\mathrm{Y}$ porq[ue] ay neçeçidad que la $\mathrm{d}$ [ic]ha obra se acabe d[e] emprimir y los d[ic]hos mis partes quieren y procuran $\mathrm{q}[\mathrm{ue}] \mathrm{se}$ acabe y no se puede azer sin q[ue] se alçe el d[ic]ho secuestro y se le entreguen la $\mathrm{d}[\mathrm{ic}] \mathrm{ha}$ emprenta con sus aparejos e letras e libros e papel q[ue] se secuestaron y el d[ic]ho salboconduto para embiar con él por mas papel a Françia, pido e sup[li] co a $\mathrm{v}$ [uestra] [roto] mande alçar y llebantar el d[ic] ho secuestro mandando que a los $\mathrm{d}[\mathrm{ic}]$ hos mis partes les sea entregada librem[ent]e la $\mathrm{d}[\mathrm{ic}]$ ha emprenta con sus letras y aparejos y los $\mathrm{d}[\mathrm{ic}]$ hos libros y papel que fue secuestrado y el $\mathrm{d}[\mathrm{ic}]$ ho salboconduto para lo qual y en lo nesçesario su rreal ofiçio de v[uestra] s[eñori]a ymploro e pido en el d[ic] ho n[omb]re, complimi[ent]o de justiçia. E juro a dios en animas de los $\mathrm{d}[\mathrm{ic}]$ hos mis partes q[ue] lo susodho no pido de maliçia.

Otrosi, para q[ue] conste como la d[ic]ha emprenta con sus letras y aparejos y el $\mathrm{d}[$ ic] ho papel se compro con los dineros que los d[ic]hos mis partes dieron al d[ic]ho Agostin de Paz para ello y q[ue] el d[ic]ho Agostin de Paz resçibio della el $\mathrm{d}$ [ic]ho salboconducto, pido e suplico a v[uestra] s[eñori]a mande al d[ic]ho Agostin de Paz jure si es verdad lo suso d[ic]ho y declarando ser asi se mande alçar el d[ic]ho secuestro y mande entregar el salboconducto y emprenta y aparejos y letras y papel a los d[ic]hos mis partes los quales siendo nesçesa[ri]o mas ynformaçion aliende del juramento y declaraçion del d[ic]ho Agostin de Paz estan prestos de la dar. ${ }^{53}-$

La respuesta no debió ser la esperada o con la inmediatez que se requería y, el 24 de septiembre de 1558, el cabildo ovetense daba poder a Pedro de Illanes, maestrescuela de Oviedo y cardenal de Santiago, a Pedro de León, administrador del Hospital Real, y a Diego de Salazar, prioste y vecino de Oviedo, para tomar las medidas legales necesarias contra Agustín de Paz por no haber respetado el contrato pues " [Agustín de Paz] se obligó de nos hacer e imprimir los brebiarios y misales y constituciones de este dicho obispado de Oviedo dentro de cierto término que es pasado". ${ }^{54}$ Un mes más tarde, el 27 de octubre, el alguacil mayor, Diego de Ribera, tomaba declaración a Paz en la prisión de Santiago como Rodrigo Fernández da Pena había solicitado. En dicha declaración, Paz reconocía que había tomado "el salboconducto del gobernador de Fuenterrabía a costa del dicho dean y cabildo" de Oviedo, que dicho salvoconducto daba licencia para que se pudiesen traer "cincuenta balas de papel a descargar en uno de los puertos de Asturias" y que "la prensa y letras y aparejos y libros de la tienda" se habían comprado con el dinero que el cabildo de Oviedo le había dado. ${ }^{55}$ El cabildo ovetense intentaba reanudar la impresión de los misales y encargaba más papel a Francia para terminarlo y al final de 1558 Rodrigo Fernández da Pena solicitaba de nuevo a la justicia la devolución del salvoconducto original para traerlo:

Muy ill[ust]r[e]s señores e muy mag[nifica]s s[eñoria]s

Rrodrigo F[ernand]es da Pena, en nombre e como p[rocurado]r q[ue] soy del dean e cavildo de la ygl[es]ia de Obiedo, digo q[ue] al t[iem]po q[ue] fue pas[ad]o

ARG. Real Audiencia de Galicia. Expedientes. Caja 418/16. Sin foliar.

ARG. Real Audiencia de Galicia. Expedientes. Caja 418/16. Sin foliar.

ARG. Real Audiencia de Galicia. Expedientes. Caja 418/16. Sin foliar. 
Agustin de Paz entre otros papeles q[ue] se le thomaron le thomaron vn salboconducto $\mathrm{q}[\mathrm{ue}]$ fue ganado con los $\mathrm{d}[\mathrm{i}] \mathrm{n}[\mathrm{er}] \mathrm{os}$ de mis $\mathrm{p}$ [ar]tes $\mathrm{p}[\mathrm{ar}] \mathrm{a}$ poder sacar papel del rreyno de Françia p[ar]a los misales e bribiarios q[ue] azia a mis $\mathrm{p}$ [ar]tes. El qual d[ic]ho salboconduto esta en poder del secr[etari]o Ares G[om]es y en el p[ro]zeso q[ue] se trata contra el d[ic]ho Agustin de Paz e Al[ons]o G[a]r[ci]a Tinajas y alli no sirbe de ni[n]g[un]a cosa e a mis $p$ [ar]tes les haze muy gran falta porq[ue] sin el no pueden sacar el $\mathrm{d}[\mathrm{ic}]$ ho papel $\mathrm{q}[\mathrm{ue}]$ tienen mandado azer y en ello rresziben dapno e p[er]dida. Por q[uanto], sup[li]co a v[uestra] $\mathrm{s}$ [eñori] a mande se entregue a mis p[art]es el d[ic]ho salboconduto original pues es suyo propio e se compro por sus d[ine]ros $\left[\ldots . .{ }^{56}\right.$

Paz moría en la cárcel de Santiago entre el 27 de octubre y el 28 de diciembre de 1558 pero el proceso contra él y sus dos socios, y la petición del cabildo de Oviedo para recuperar el material de imprenta y el salvoconducto, no se detuvieron aquí. ${ }^{57}$ El 7 de enero de 1559 el cabildo de Oviedo presentaba una requisitoria y, dos días después, se comenzaba a interrogar a los testigos. Todos confirmaban los pagos y adelantos que se le habían hecho a Paz y los 300.000 maravedís que había costado la impresión del breviario, y todos declaraban la difícil situación económica en la que Paz había llegado a Oviedo, cómo "andaba siempre importunando por dineros" y no dejaba "en su casa provisión de mantenimientos a los oficiales" cuando iba a Francia, y las numerosas deudas que tenía en Santiago, Lugo, Medina del Campo "y otras ferias". ${ }^{58}$ El 17 de febrero de 1559 Andrés López, en nombre del cabildo ovetense, presentaba libranzas y conocimientos del propio Paz para demostrar todos los pagos que se le habían hecho, un traslado del contrato que habían firmado Paz y el cabildo en 1555, y la entrega de 450 ducados que se había hecho a Paz antes de iniciar la impresión de las obras contratadas. ${ }^{59}$

En junio de 1559 el proceso contra Paz, García Tinajas y Florín todavía seguía adelante y, el 3 de ese mismo mes, Ambrosio Rótulo, persona encargada de la impresión de bulas en Valladolid, otorgaba poder a Álvaro Díaz, Rodrigo Ninez y Andrés López, procuradores de causas en la Audencia Real de Galicia, para que presentasen el título que éste tenía para dicha impresión, e hiciesen valer sus derechos en la causa contra Paz. El proceso contra Paz y sus socios debió resolverse durante los meses siguientes. Paz, García Tinajas y Florín fueron considerados culpables y, como consecuencia, dos terceras partes de sus bienes fueron confiscadas. El 5 de septiembre de 1559 Rodrigo Ninez, como procurador de Ambrosio Rótulo, presentaba algunas provisiones reales para demostrar los derechos de éste sobre la impresión de bulas y solicitar la entrega a su cliente de una parte de estos bienes confiscados. ${ }^{60}$

La documentación de la petición del cabildo ovetense para la devolución del

ARG. Pillado. Mazo 2. Núm. 16. Leg. 418. Sin foliar.

El 27 de octubre de 1558, el alguacil mayor, Diego de Ribera, tomaba juramento a Agustín de Paz dentro de la carcel pero el 28 de diciembre de ese mismo año se notificaba una provisión a Beatriz López como "mujer viuda que fué y quedó de Agustín de Paz”. ARG. Pillado. Mazo 2. Núm. 16. Leg. 418. Sin foliar.

58 ARG. Real Audiencia de Galicia. Expedientes. Caja 418/16. Sin foliar.

59 ARG. Real Audiencia de Galicia. Expedientes. Caja 418/16. Sin foliar.

60 ARG. Real Audiencia de Galicia. Expedientes. Caja 26581/93. Sin foliar. 
material de imprenta secuestrado a Paz no da detalles de cómo se resolvió dicho causa, pero los ejemplares conservados del misal y la documentación catedralicia indican que la imprenta, el salvoconducto para traer papel de Francia, y los libros y pliegos del misal fueron devueltos al obispado ovetense en 1559. El cabildo ovetense terminaría de imprimir el misal durante los últimos meses de ese mismo año y, aunque desconocemos a los responsables de dicho trabajo, no se puede descartar que fuese realizado por el propio Florín y los antiguos oficiales de Paz. El 17 de noviembre de 1559 el cabildo pedía a los canónigos Fernando de Valdés y Juan de Valledor que se reuniesen "con los señores que hacen el misal para lo ver" ${ }^{61}$ El 24 de noviembre de 1559 se ordenaba a Fernando de Valdés, Juan de Valledor, Gonzalo de Solís y Bartolomé Ribera "ver los misales con su señoría y dar apuntamientos para lo que conviene remediar". ${ }^{62}$ En los primeros meses de 1560 probablemente se comenzó la distribución de los misales en el obispado y a disponer qué hacer con el material de Paz. El 10 de enero de 1560 el cabildo pedía "la visita de la librería [de Paz?]" para "aprobar los [libros] buenos", titularlos y hacer inventario de ellos. ${ }^{63}$ Una semana después, el cabildo pedía al arcediano de Villaviciosa, a Pedro de Castro, a Fernando de Valdés y a Pedro de Portillo que vendiesen los breviarios, que quizás habían encontrado en la librería, y que se ordenasen "otros [breviarios] nuevos porque conviene", y lo hablasen con el obispo." ${ }^{\prime 64}$ Un mes después, el cabildo mandaba "dar libramiento [...] de cuatro mil maravedís que el señor administrador ha de pagar por la casa de [...] la imprenta y ha de asentarse a cuenta de los misales." 65

El proyecto reformador y editorial de Cristóbal de Rojas y del cabildo ovetense se completaba sólo después de cinco azarosos años. Las numerosas deudas de Agustín de Paz, la decisión de mantener abierto su taller y librería en Santiago, y su participación en la publicación de bulas falsas determinaron la historia de este ambicioso proyecto editorial diocesano que, sin embargo, no tendría futuro. Las sesiones de Trento se reanudaban en 1562 - tan solo dos años después de la distribución del misal ovetense - y en la última asamblea tridentina de 1563 se decidía la unificación de todos los libros litúrgicos. Las misales y breviarios ovetenses serían prohibidos y destruidos y la historia de importantes proyectos editoriales como el de Rojas pasarían al olvido.

\footnotetext{
61 ACO. Acuerdos Capitulares. Libro 9. Fol. 72R.

62 ACO. Acuerdos Capitulares. Libro 9. Fol. 72V. Una descripción del misal oventense en Odriozola, $1996: 225$. Una descripción del misal oventense en Odriozola, A. 1996: 117.

63 ACO. Acuerdos Capitulares. Libro 9. Fol. 80R.

64 ACO. Acuerdos Capitulares. Libro 9. Fol. 81V.

65 ACO. Acuerdos Capitulares. Libro 9. Fol. 86R.
} 


\section{Referencias bibliográficas}

Cabano, I. (1995). Mare libri brumale navigando. Las ediciones de la Descripción del Reyno de Galizia del Licenciado Molina. Museo de Pontevedra, 49, 433-456.

Fernández Álvarez, M.; Tuero Bertrand, F.; González Novalín, J. J. (1977). Historia de Asturias. Edad Moderna I. Oviedo: Ayalga

Flórez, H. (1795). España Sagrada. Vol. 38. Madrid.

García y García, A. (dir.) (1984). Synodicon Hispanum III. Astorga, León, Oviedo. Madrid: Biblioteca de Autores Cristianos.

García y García, A. (1999). La colección sinodal Lamberto de Echevarría y el Synodicon Hispanum, en Sínodos diocesanos y legislación particular. Estudios históricos en honor al Dr. D. Francisco Cantelar Rodríguez. Salamanca: Universidad Pontifica, 25-43.

González Novalín, J. L. (1968). El inquisidor general Fernando de Valdés (1483-1568): su vida y su obra. Oviedo: Universidad de Oviedo.

Goñi Gaztambide, J. (1958). Historia de la bula de la cruzada en España. Vitoria: Editorial del Seminario.

Gutierrez, C. (1951). Españoles en Trento. Valladolid: Consejo Superior de Investigaciones Científicas.

López de Ayala, I. (trad.) (1828). El Sacrosanto y Ecuménico Concilio de Trento. Barcelona: Sierra y Martì.

Martín Abad, J. (1991). La Imprenta en Alcalá de Henares (1502-1600). Vol. 1. Madrid: Arco Libros

Odriozola, A. (1974). Imprenta, en Gran Enciclopedia Gallega. Vol. 17. Santiago de Compostela: Silverio Cañada, 240-256.

Odriozola, A. (1996). Catálogo de libros litúrgicos españoles y portugueses impresos en los siglos XV y XVI. Pontevedra: Museo de Pontevedra.

Rial Costas, B. (2007). Producción y comercio del libro en Santiago de Compostela (15011553). Madrid: Calambur y Consorcio de Santiago.

Serrano Morales, J. E. (1898-1899). Reseña histórica en forma de diccionario de las imprentas que han existido en Valencia desde la introducción del arte tipográfico en España hasta el año 1868 con noticias bio-bibliográficas de los principales impresores. Valencia: Imprenta de F. Domenech. 